Pig Housing and the Environment

Occasional Publication No. 11-British Society of Animal Production 1987

edited by A. T. Smith and T. L. J. Lawrence

\title{
INTERNAL AIR FILTRATION FOR EARLY-WEANED PIGS
}

\author{
G. A. CARPENTER
}

AFRC Institute of Engineering Research, Silsoe, Bedford MK45 $4 H S$

$\mathbf{T}$ The effects of using an internal recirculating air filter in a room containing early-weaned pigs has been investigated.

The filter unit consisted of a floor-standing suction box fitted with $2 \mathrm{~m}^{2}$ of filter material. The fan, of capacity $1 \mathrm{~m}^{3} / \mathrm{s}$, discharged air from the suction box into two ducts spanning the lying areas of all the pens. The ducts were tapered to give uniform air distribution and the undersides were covered with a filter material finer than that on the first filter. Filtered air was discharged through the material at a velocity of $0.4 \mathrm{~m} / \mathrm{s}$ vertically downwards towards the lying areas of the pens. The filtration system was independent of the ventilation system, its fan capacity being approximately equal to the maximum ventilation rate. The maximum pressure loss across each filter was 6 to $8 \mathrm{~Pa}$. The nominal particle retention sizes for the first and second stage filters were 5 and $3 \mu$ n respectively. Pressure-loss gauges were fitted across each filter and that across the first stage was fitted with an alarm set to 6 to $8 \mathrm{~Pa}$. This entailed vacuum cleaning the filter surface about every 5 days. The pressure loss across the second stage filter reached 6 to 8
Pa only after several weeks. Both filters were replaced after each batch of pigs, but the first stage filter could have been used for a longer period. The power consumed by the filter unit fan was $400 \mathrm{~W}$. As this is dissipated as heat inside the building, it supplements the heaters at times when heating is required.

In the experiments, filter units were installed in early-weaner rooms on three separate farms one having a specific pathogen free (SPF) herd and the other two having herds with respiratory disease. The room adjacent to the one containing the filter unit was used as a control. On average, concentrations of dust mass and also bacterial colony-forming particles were reduced proportionately by $0 \cdot 60$, and the weight of dust collected was of the order of $2 \mathrm{~g}$ per piglet per day (age 3 to 7 weeks). No effect on growth rate was observed on the pigs leaving the room but in both the herds that had respiratory disease, the time taken to reach a marketable weight was reduced by 5 to 8 days. The lungs from the pigs of one of these herds was examined and filtration was found to have reduced the severity of damage. Pigs from the SPF herd showed no benefit. 